\title{
Influence of Palmitic Acid and Amino Acids Addition on Iturin A Productivity by Bacillus subtilis RB14-CS
}

\author{
Y U L I A R \\ Microbiology Division, Research Center for Biology, The Indonesian Institute of Science, Bogor 16002.
}

Received: 8 January 2005. Accepted: 5 April 2005.

\begin{abstract}
The aim of this study was to observe the influence of palmitic acid and amino acids on enhancement of iturin A productivity using Bacillus subtilis RB14-CS. The concentrations of palmitic acid examined were $0.8 \%, 1.6 \%$, and $3.2 \%$. A good yield was observed when $1.6 \%$ palmitic acid was added to Polypepton $S$ medium. The production of iturin A increased about $18 \%$ than the control. Addition of $3.2 \%$ palmitic acid was not effective on iturin A production. It gave lower $\mathrm{pH}$ and slightly higher viable cell number of RB14-CS than control and the others addition concentration. Whereas the addition of $0.8 \%$ of each of the following amino acids; L-arg, L-asn , L-gln , L-glu, L-gly, Lleu, L-lys, L-trp, L-tyr, and L-val could not increase iturin A productivity, but changed the proportion of iturin A peaks. L-leu, L-val, and L-asn addition produced the highest proportion of peak 3,4 , and 1 respectively.
\end{abstract}

Key words: iturin A, Bacillus subtilis RB14-CS, palmitic acid, and L-amino acids.

\section{INTRODUCTION}

The use of microorganisms for biological purposes has become an effect to control plant pathogens. Various strains of Bacillus subtilis (NB22, YB8, UB24, and SB4) suppressed phytopatogenic fungi or bacteria in vitro and greenhouse test (Phae et al., 1990). Berna et al., (2002) demonstrated that mutant strain of Bacillus sp. has a higher antagonistic activity against the plant pathogen Botrytys cinera (grey mould), Rastonia solanacearum (bacterial wilt) and Erwinia carotovora (bacterial soft rot).

As producer of antibiotics, Bacillus spp. secrete three groups of the following lipopeptide antibiotics; surfactin group, iturin group, and plipastatin- fengycin group (Tsuge et al., 2001). Among of these antibiotics, iturin has the strongest antifungal activity on large variety of yeasts and fungi. As iturin $A$ is one of the most powerful antifungal substance, it has good prospect on agriculture and medical application. Since Bacillus produce the lipopeptide antibiotics, therefore why this bacteria suppres various plant pathogens. Iturin families that were found are; iturin A, iturin $C$, iturin $D$, iturin $E$, baccilomycin $D$, bacillomycin $F$, bacillomycin $\mathrm{L}$. Iturin $\mathrm{A}$ consist of five homologues and the five peaks pattern of iturin A as shown in Figure1.

The highest productivity of iturin A was $138 \mathrm{mgl}^{-1}$, produced by Bacillus subtilis S499 (Hbid et al., 1996). Beside carbon and nitrogen source, palmitic acid and Lamino acid may also influence the antibiotics production. Palmitic acid was incorporated into lipid moiety of iturin A by $B$. subtilis on Landy medium (Besson et al., 1990). The metabolism of amino acids, purine, and pyrimidines provides the nitrogenous precursor for antibiotics biosynthesis.

\footnotetext{
- Alamat korespondensi:

JI. Ir. H. Juanda 18 Bogor 16002

Tel.: +62-251-321038, Fax.: +62-251-325854

e-mail: novikur@yahoo.com
}

Specific amino acids are direct precursors for many peptide antibiotics (Aharonowitz, 1980). In order to know whether palmitic acid or L- amino acid can enhance iturin $A$ productivity, the addition effect of them to the medium cultivation of Bacillus subtilis RB14-CS was studied.

\section{MATERIALS AND METHODS}

Microorganism. Bacillus subtilis RB14-CS as mono producer of iturin A was used in this study. This microorganism is belong to Prof. Makoto Shoda laboratory (Chemical Resources Lab., Tokyo Institute of technology).

LB medium. This media were used as seed media and consist of $10 \mathrm{~g} / \mathrm{l}$ polypepton, $5 \mathrm{~g} / \mathrm{l}$ yeast extract, and $5 \mathrm{~g} / \mathrm{l}$ $\mathrm{NaCl}$. The $\mathrm{pH}$ was adjusted to 7.00 with $\mathrm{NaOH}$. Five milliliters of this media were transferred into a test tube using micropipette and sterilized at $121^{\circ} \mathrm{C}$ for 20 minutes. For LB agar media, $2 \%$ of agar was added to the media

Polypepton S medium. Polypepton S (3.2 g) were dissolved in $23 \mathrm{ml}$ distilled water in $200 \mathrm{ml}$ flasks and sterilized at $121^{\circ} \mathrm{C}$ for $20 \mathrm{~min}$. After sterilization, $6.7 \%$ of maltose, $0.5 \% \quad \mathrm{~K}_{2} \mathrm{HPO}_{4}, \quad 0.05 \% \quad \mathrm{MgSO}_{4} .7 \mathrm{H}_{2} \mathrm{O}, \quad 25 \mathrm{ppm}$ $\mathrm{FeSO}_{4} .7 \mathrm{H}_{2} \mathrm{O}, 22 \mathrm{ppm} \mathrm{MnSO}_{4} .5 \mathrm{H}_{2} \mathrm{O}$, and $184 \mathrm{ppm}$ $\mathrm{CaCl}_{2} \cdot 2 \mathrm{H}_{2} \mathrm{O}$ were added into flasks.

Pre-cultivation. Five milliliters sterilized LB media in a test tube were added with $5 \mu \mathrm{l}$ of streptomycin $\left(20 \mathrm{mgl}^{-1}\right)$ and inoculated with $10 \mu \mathrm{l}$ of RB14-CS stock. Inoculated media was incubated at $37^{\circ} \mathrm{C}$ and shake $124 \mathrm{spm}$ (horizontal shaker) for about 16 hours.

Cultivation of RB14-CS on Polypepton S media contains palmitic acid. Three concentrations of palmitic acid i.e $0.8 \%, 1.6 \%$, and $3.2 \%$ were each added into polyppeton S media and inoculated with $400 \mu$ RB14-CS, then incubated at $30^{\circ} \mathrm{C}, 120 \mathrm{spm}$ for 7 days.

Cultivation of RB14-CS on Polypepton $S$ that contains L-amino acids. $0.8 \%$ of each of L-amino acid i.e L-arg, L-asn , L-gln , L-glu, L-gly, L-leu, L-lys, L-trp, L-tyr, 


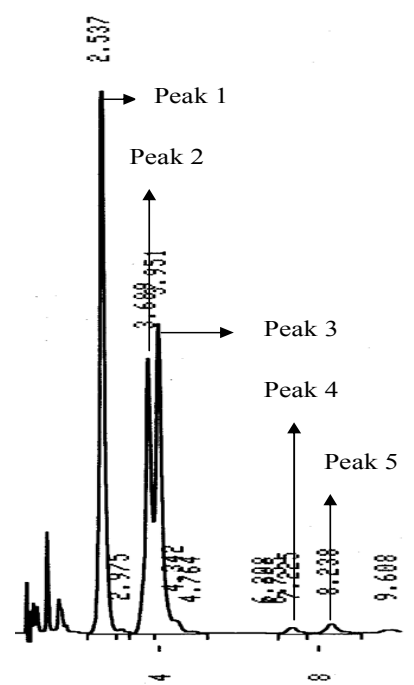

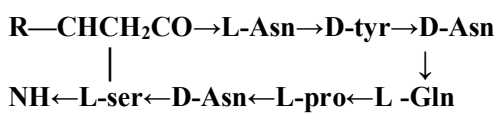

R

$\beta$-amino acid group

Peak $2 \mathrm{CH}_{3}-\mathrm{CH}_{2}-\mathrm{CH}_{2}$-anteiso-C15- $\beta$-amino acid $\mathrm{CH}_{3}$

Peak $3 \mathrm{CH}_{3}$-CH-CH $\mathrm{H}_{2}$-iso-C15- $\beta$-amino acid $\mathrm{CH}_{3}$

Peak $4 \mathrm{CH}_{3}-\mathrm{CH}-\mathrm{CH}_{2}-\mathrm{CH}_{2}$-iso-C16- $\beta$-amino acid $\mathrm{CH}_{3}$

Peak $5 \mathrm{CH}_{3}-\mathrm{CH}_{2}-\mathrm{CH}_{2}-\mathrm{CH}_{2}--\mathrm{C} 16-\beta$-amino acid

addition. The $\mathrm{pH}$ change in the sample with the addition of $0.8 \%$ and $1.6 \%$ palmitic acid was almost similar with the control. The range of viable cell number change of the strain was $10^{10}$ to $10^{8} \mathrm{CFU} / \mathrm{ml}$.

Figure 4 below illustrates iturin $\mathrm{A}$ productivity in the presence of $0.8 \%$ of each of the following amino acids; L-arg, L-asn , L-gln , L-glu, L-gly, L-leu, L-lys, L-trp, L-tyr, and L-val on Polypepton $S$ medium. The addition of these L-amino acids did not improve the iturin A productivity, but changed the proportion of iturin A peaks (Figure 5). Whereas suplementation of L-amino acids changed the proportion of iturin A peaks. HPLC separation pattern of iturin A homologous is denoted as peak 1 to peak 5 according to elution time order of HPLC. Each of them (peaks 1 to 5) corresponds to the following components respectively; $n$-C14- $\beta$-amino acid, anteiso$C 15-\beta$-amino acid, iso- $C 15-\beta$-amino acid, isoC16- $\beta$-amino acid, and $n$-C16- $\beta$-amino acids (Fig. 1). When L-leu was supplemented to the and L-val were added into Polypepton $\mathrm{S}$ medium before autoclaving. Sterilized media were inoculated with $400 \mu \mathrm{l}$ RB14-CS, then incubated at $30^{\circ} \mathrm{C}, 120 \mathrm{spm}$ for 7 days.

Extraction and measurement of iturin $\mathrm{A}$. The culture $(100 \mu \mathrm{l})$ were transferred into one milliliter Eppendorf tube, and diluted with $900 \mu \mathrm{l}$ of the buffer that composed of $\mathrm{CH}_{3} \mathrm{CN}: 10 \mathrm{mM} \mathrm{CH}_{3} \mathrm{COONH}_{4}(35: 65 ; \mathrm{v} / \mathrm{v})$. The mixture were rotated for about 30 minutes at room temperature, and it were centrifuged at $15,000 \mathrm{xg}$ for 10 minutes at $4^{\circ} \mathrm{C}$. The supernatant were filtrated through $0.20 \mu \mathrm{m}$ PTFE membrane filter (Advantec 020). This filtrate $(20 \mu \mathrm{l})$ were injected into ODS RP-18C (Merck) column, and monitored by the UV detector at $205 \mathrm{~nm}$ (LC-800 system, JASCO). HPLC was performed using acetonitrile: $10 \mathrm{mM} \mathrm{CH}_{3} \mathrm{COONH}_{4}=(35: 65$, $\mathrm{v} / \mathrm{v}$ ) solvent, and flow rate was $2 \mathrm{ml} / \mathrm{min}$, and absorbance were measured at $30^{\circ} \mathrm{C}$. Iturin A production was observed on day 2 , day 5 , and day 7 .

Viable cell number. The culture was diluted $10^{7}$ times in small sterile test tubes, then $100 \mu$ of the dilution sample was spread onto the LB agar medium. After the plates were incubated in incubator at $37^{\circ} \mathrm{C}$ overnight, the cell number was counted. The viable cell number was observed on day 2 , day 5 , and day 7 .

\section{RESULTS AND DISCUSSION}

As we see in figure2, the addition of $1.6 \%$ palmitic acid on Polypepton $\mathrm{S}$ medium enhanced iturin $\mathrm{A}$ production $18 \%$. Without an addition the production was about 2200 $\mathrm{mgl}^{-1}$ and the addition of $1.6 \%$ of palmitic acid yielded iturin A about $2600 \mathrm{mgl}^{-1}$. This is in agreement with Hourdou et al. (1988) who reported that by $0.05 \%$ of palmitic acid addition to the culture medium (LANDY medium), iturin A $\beta$-amino acids by GC analysis showed an increase of straight chain $\beta$-amino acids: $33 \%$ instead of $24 \%$ in the control for $n-C_{14}$ and $11 \%$ instead of $6 \%$ in the control for $n-C_{16}$. Besson et al. (1990) also reported that palmitic acid is the precursor of $\beta$-amino acids of iturin $A$.

Figure 3 shows the $\mathrm{pH}$ range and viable cell number of RB14-CS on iturin A productivity. A high concentration of palmitic acid addition (3.2\%) was not effective in iturin $A$ production. It gave lower the $\mathrm{pH}$ and slightly higher of the viable cell number than control and the others concentration

cultivation of RB14-CS the highest proportion of peaks 3 (iso- $C 15-\beta$-amino acid) of iturin $A$ was observed. Hourdou et al. (1988) observed that leucine increased the production of iso-C15- $\beta$-amino acid and iso-C15 fatty acid of iturin A. While Besson and Hourdou (1987) observed the influence of leucine on bacillomycin $F$ production, and they found that leucine increased both odd iso fatty acid and odd iso $\beta$ amino acids to about $55 \%$. By addition of L-val to the cultivation, the strain produced the highest proportion of peak 4 (iso-C16-ßamino acid). Hourdou et al. (1988) reported that valine was found to increase iso-C16 and $n$ C14- $\beta$-amino acid of iturin A. Besson and Hourdou (1987) found that valine increased iso $\mathrm{C}-14$ and $\mathrm{C}-16$, but did not induce synthesis of iso-C14- $\beta$-amino acid on bacillomycin production. Akpa et al. (2001) also stated that valine is a precursor of even fatty acids, and the use of leucine increased the rate $C 15-\beta$-amino acid (44\%). Theobald et al. (2000) observed that in a chemically defined medium, L-val was better nitrogen source than L-glu and L-leu for the simocyclinone D8 production. Whereas Kempf et al., (1999) increased gallidermin production to about $25 \%$ by Staphylococcus gallinarum by the addition of glutamic acid (final concentration $20 \mathrm{gl}^{-1}$ ) at fermentation time of 30 hours.

The viable cell number and the pattern of $\mathrm{pH}$ change of L-amino acids supplementation was almost similar to the control one (Table 1). The addition of L-asn gave the smallest cell number on day five, after that all of cell number decreased to about $10^{8} \mathrm{CFU} / \mathrm{ml}$.

Table 1. $\mathrm{pH}$ and viable cell number in amino acids experiment shown in figure 4.

\begin{tabular}{lcccccc}
\hline \multirow{2}{*}{ Treatment } & \multicolumn{3}{c}{ Viable cell number $\left(\mathbf{\times 1 0 ^ { 9 }}\right.$} & \multicolumn{3}{c}{ pH } \\
\cline { 2 - 7 } & \multicolumn{3}{c}{ CFU/ml) } & & & \\
\cline { 2 - 7 } & Day 2 & Day 5 & Day 7 & Day 2 & Day 5 & Day 7 \\
\hline Control & 13.9 & 10.1 & 0.15 & 7,62 & 8.75 & 9.18 \\
L-arg & 16.0 & 3.4 & 0.15 & 7,95 & 9,06 & 9.06 \\
L-asn & 9.1 & 1.0 & 0.11 & 7,71 & 9.09 & 9.14 \\
L-gln & 11.6 & 10.4 & 0.01 & 7.94 & 8.92 & 9.16 \\
L-glu & 9.9 & 1.13 & 0.10 & 8.01 & 8.20 & 9.23 \\
L-gly & 9.1 & 8.4 & 0.12 & 7.76 & 8.60 & 9.16 \\
L-leu & 14.8 & 13.2 & 0.20 & 7.73 & 8.02 & 8.87 \\
L-lys & 14.1 & 14.4 & 0.20 & 7.54 & 8.49 & 8.85 \\
L-trp & 14.4 & 5.60 & 0.27 & 7.43 & 8.78 & 9.04 \\
L-tyr & 14.9 & 9.20 & 0.22 & 7.47 & 8.83 & 9.04 \\
L-val & 13.6 & 12.80 & 0.01 & 7.59 & 7.46 & 8.76 \\
\hline
\end{tabular}




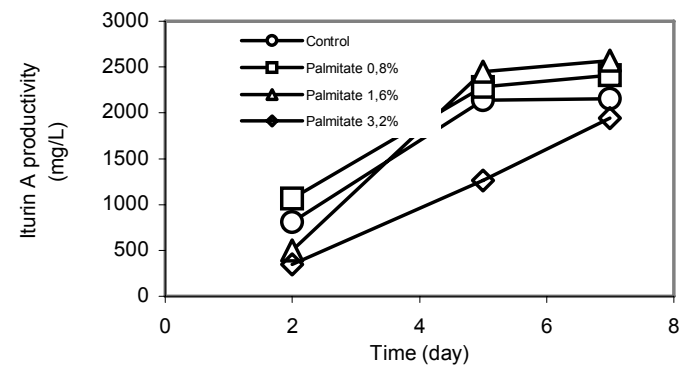

Figure 2. Influence of palmitic acid on iturin A productivity.

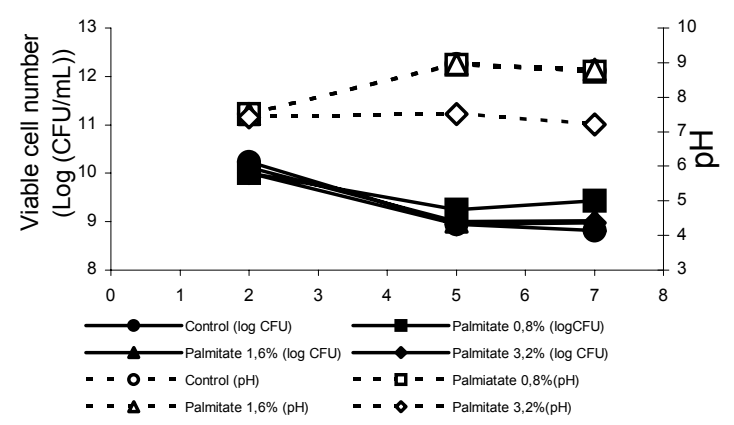

Figure 3. Viable cell number and $\mathrm{pH}$ changes in the palmitic acid addition experiment.

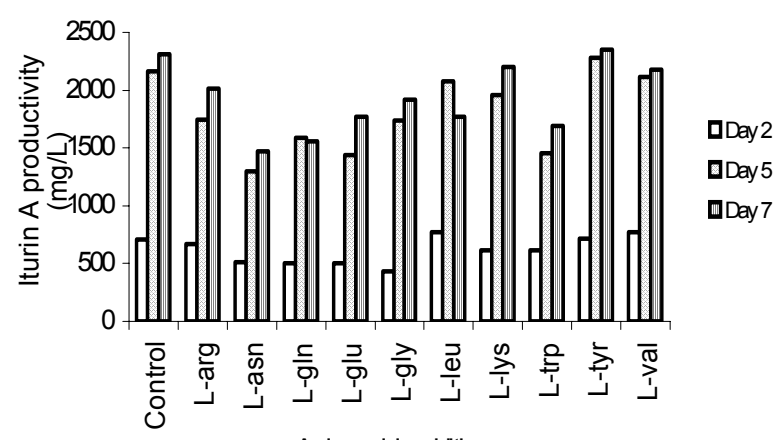

Aminoacids addition

Figure 4. The influence of amino acids on iturin A productivity.

\section{CONCLUSION}

This research can be concluded as follows: (i) supplementation of $1.6 \%$ palmitic acid to the Polypepton $S$ medium increased the production of iturin $\mathrm{A}$ about $18 \%$, (ii) the addition of $0.8 \%$ of each the following amino acids $L$ arg, L-asn, L-gln, L-glu, L-gly, L-leu, L-lys, L-trp, l-tyr, and Lval could not increase iturin $A$ production, but change the peaks proportion of iturin A, (iii) L-leu addition produced the highest proportion of peak 3 , L-val addition gave the highest proportion of peak 4 , and L-asn addition resulted the highest proportion of peak 1 .

\section{ACKNOWLEDGEMENTS}

I would like to thank Prof. Makoto Shoda and Prof. Takashi Ano, Chemical Resources Laboratory, Tokyo Institute of Technology for their helpful guidance, and comments during this study. I also thank Dr. Kazumasa Okuno for his assistance and comment during the experimental work.
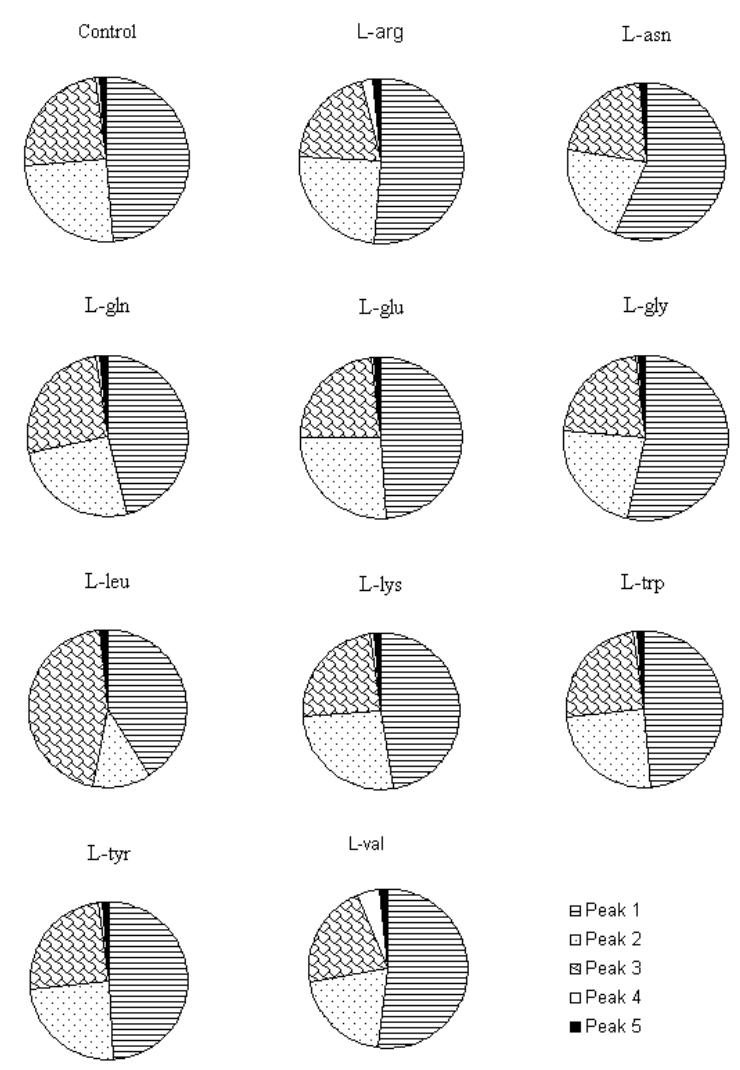

Figure 5. The influence of amino acids addition on the peaks proportion of iturin $\mathrm{A}$.

\section{REFERENCES}

Aharonowitz, Y. 1980. Nitrogen metabolite regulation of antibiotic biosynthesis. Annual Review of Microbiology 34: 209-233.

Akpa, E., P. Jacques, B. Wathelet, M. Paquot, R. Fuch, H. Budzikiewicz, and P. Thonart. 2001. Influence of culture conditions on lipopeptide production by Bacillus subtilis. Applied Biochemistry and Biotechnology 91/93: 551-556.

Berna,G., A.. Illanes, and L. Ciampi. 2002. Isolation and partial purification of metabolite from a mutant strain of Bacillus $\mathrm{sp}$. with antibiotic activity against plant pathogenic agents. Electronic Journal of Biotechnology 5: 1-9.

Besson, F. and M.L. Hourdou, 1987. Effect of amino acids on the biosynthesis of amino acids constituents of Bacillomycins F. Journal of Antibiotics 40: 221-223.

Besson, F., M.L. Hourdou, and G. Michel, 1990. Studies on the biosynthesis of iturin, an antibiotics of Bacillus subtilis, and lipopeptide containing $\beta$ hydroxy fatty acids. Biochemistry and Biophysics Acta 1036: 101-106.

Hbid ,C., P. Jacques, H. Razafindralambo, M.K. Mpoyo, E. Meurice, M. Paquot, and P. Thonart, 1996. Influence of the production of two lipopeptides, iturin $A$ and surfactin $S 1$, on oxygen transfer during Bacillus subtilis fermentation. Applied Biochemistry and Biotechnology 57/58: 572-579.

Hourdou, M. L., F. Besson, and G. Michel, 1988. Studies on the biosynthesis of $\beta$-amino acids, the lipid moiety of iturin $A$, in Bacilllus subtilis. Journal of Antibiotics 41: 207-211.

Kempf, M., U. Theobald, and H.P.Fiedler, 1999. Correlation between the consumption of amino acids and the production of the antibiotic gallidermin by Staphylococcus gallinarum. Biotechnology Letters 21: 959-963.

Phae, C.G., M. Shoda, and H. Kubota, 1990. Suppressive effect of Bacillus subtilis and its product on phytopathogenic microorganisms. Journal of Fermentation and Bioengineering 69: 1-7.

Theobald, U., J. Schimana, and H. Fiedler. 2000. Microbial growth and production kinetics of Streptomyces antibioticus Tu 6040. Antonie van Leeuwenhoek 78: 307-313.

Tsuge, K., T. Akiyama, and M. Shoda, 2001. Cloning, sequencing, and characterization of iturin A operon. Journal of Bacteriology 183: 62656273 